\title{
Investigation on the Effectiveness of Treatments for Overcoming Emotional, Mental and Physical Health Problems
}

\author{
Siew Hock Ow (Corresponding author) \\ Department of Software Engineering \\ Faculty of Computer Science \& Information Technology \\ University of Malaya \\ 50603 Kuala Lumpur, Malaysia \\ Tel: 603-79-676-366Ｅ-mail: show@um.edu.my \\ Muhammad Haroon \\ Department of Software Engineering \\ Faculty of Computer Science \& Information Technology \\ University of Malaya \\ 50603 Kuala Lumpur, Malaysia
}

Tel: 92-33-2311-9695Ｅ-mail: sm_haroon@yahoo.com

\author{
Afzal Hussain \\ Department of Software Engineering \\ Faculty of Computer Science \& Information Technology \\ University of Malaya \\ 50603 Kuala Lumpur, Malaysia
}

Tel: 92-30-2287-8947

E-mail: afzhussain@yahoo.com

\begin{abstract}
This study is aimed at investigating the effectiveness of various treatments to overcome emotional, mental and physical (EMP) health problems among medical students in Pakistan. The EMP health is assessed using two questionnaires. The effectiveness of treatments to overcome EMP health problems was evaluated using statistical paired t-test on 113 medical students. 'Soothing the body and the mind' and 'Collarbone breathing exercise' are found to be most effective methods of treatment for emotional health problem. All treatments for EMP health problems are found to be effective if the respondents performed the treatments regularly.
\end{abstract}

Keywords: Emotional, Mental, Physical health, Treatment effectiveness, Paired-t Test

\section{Introduction}

Health is viewed holistically as an interacting system of the mental, emotional and physical mechanisms of the body. It is the ability to suitably determine difficulties and control emotions that is the source of preserving and articulating positive self-concept and physical and mental well-being. Thus, it is very important to look at health as a multidimensional phenomenon, with emotional, mental and social perspectives that are inseparable from one another. Today, emotional, mental, and physical health problems are serious problems in both developed and developing countries. This is evident from the increasing number of tragic and fatal incidents that happened in schools, colleges, and universities in the West as well as in the East. These include the tragic killing of 32 people by Cho Seung-Hui, a South Korean student, at Virginia Tech (Hopkins \& Zengerle, 2008; Thomson Reuters, 2008). In another incident, Sajjad Abbasi committed suicide out of frustration and due to the continuous reprimand by his parents for not getting prominent position in the SSC examination (PakTribune, 2008). Also, another incident happened in Malaysia, where a 12-year old girl committed suicide at her home for not obtaining the results 
that she had expected in the Primary School Assessment Examination results (AsiaOne News, 2007). These sad incidents reflect that students who suffer from EMP health problems are shy or hesitant to seek advice or seek treatment from psychiatrists. According to Dr. Mohamad Hussain Habil, Head of the Department of Psychological Medicine, University of Malaya, people who have anxiety problems, and are suffering from depression or any psychiatric disorders, should see a psychiatrist without hesitation (Dass, 2007).

Needless to say, the emotional, mental and physical health problems of people in educational institutions can have serious consequences both for the individuals and for society. Health status can affect student performance, class attendance, motivation and morale, grades and rate of drop-outs (Arthur, 1998; Haines, Norris \& Kashy, 1996). Such problems affect not only individuals, but also the entire community through the direct costs of welfare services and treatment, and loss of income as a result of incapacity. Thus, researches are still going on to find a good integrated EMP health assessment technique that can also recommend effective treatments to help overcome EMP health problems.

In Pakistan, medical universities/colleges are often regarded as tense environments that can have negative impacts on the emotional, mental, physical, and psychological well-being of the students. In a study, Inam, Saqib, and Alam (2003) of Ziauddin Medical University, Karachi, Pakistan, found that $60.0 \%$ of the medical students have anxiety problem and they suffer from depression. This finding is consistent with the results of similar studies done in the West.

Thus, this research is aimed at investigating and establishing an integrated EMP health assessment technique that not only can analyse the EMP health status of the medical students but also recommend treatments to overcome EMP health problems. The following sections discuss the methods used in this study, and the investigation carried out to evaluate the effectiveness of various treatments for overcoming EMP health problems.

\section{Research methods}

In this research, a thorough literature review was first conducted on EMP assessment techniques. Four EMP health assessment techniques were reviewed and compared. These include the Emotional Freedom Technique (EFT) (Quantum Flow, 2007); Zensight Energy Healing Technique (Zensight Energy Healing, 2005); Thought Field Therapy (TFT) technique (South West Clear Mind, n.d.); and Vera Peiffer's technique published in her bestselling book (Peiffer, 2002), Inner Happiness: Positive Steps to Feeling Complete. Vera Peiffer's technique was selected as it is the most comprehensive and adopts an integrated approach. It analyses EMP health conditions and suggests treatments to overcome the health problems detected. The technique is deemed to be reliable and effective as Vera Peiffer is a qualified analyst/hypnotherapist and health kinesiologist (Peiffer, 2002).

To assess the EMP health status of the medical students (respondents), two questionnaires were formulated using questions recommended by Vera Peiffer. The first questionnaire (a pre-test questionnaire) aims to assess the preliminary EMP health status. The second questionnaire aims to assess the severity level of the EMP health problems of the respondents. The second questionnaire is used "before and after treatments" so that the results of the two assessments can be compared to determine whether there has been improvement in the EMP health status after treatment.

The surveys, using the questionnaires, were carried out to investigate the preliminary EMP health condition of the respondents (pre-test) and the severity level of those respondents who suffer from EMP health problems (before-treatment test) (Peiffer, 2002). The respondents who suffer from EMP health problems were recommended appropriate treatments. Re-assessment on the EMP health of the respondents was conducted after the treatment periods (after-treatment test). An assessment of the effectiveness of the EMP health treatments was made using the statistical paired-t test.

The medical students involved in this research are from three different medical institutions in Pakistan - Baqai Medical University, Dow University of Health Sciences, and Sindh Medical College.

\section{Questionnaire survey}

The survey method was used to collect the personal health status pertaining to emotional, mental and physical health of the medical students. The data collected was used to analyse the respondents' health status, and appropriate treatments were recommended to those respondents who have EMP health problems. Before the actual survey was carried out, a pilot test was conducted by inviting 30 medical students to answer the questionnaires in order to solicit feedback on the survey questionnaire. The feedback revealed mistakes that have been overlooked and other issues that have not been considered. After the pilot study, corrections were made to the two original questionnaires to make the questionnaires easy to understand and answer.

In order to manage the research study effectively, a Web-based system, EMPHA Health Analyser, was developed. The EMPHA Health Analyser allows the medical students (respondents) to keep track of the treatments/exercises performed by them. To study the effectiveness of treatments, respondents must perform the treatments assigned to them for at least six months. Hence, in this research, a Web-based questionnaire survey using the EMPHA system was carried out for six months, from August 2006 to January 2007. 


\subsection{Questionnaire Design}

As mentioned above, two questionnaires were used to collect data from the respondents. In the first questionnaire (pre-test), respondents are only required to choose either a 'Yes' or 'No' option for all the assessment statements (Appendix I). In the second questionnaire (before and after treatment tests), a 6-point Likert scale was used for the response to all the assessment statements (Appendix II). The respondents answer this questionnaire before and after treatments.

The two questionnaires were incorporated into the EMPHA Health Analyser. Thus, the system is able to make an assessment of EMP health status, recommend treatments based on the assessment results, monitor treatments performed, and compare EMP health status accurately and efficiently. The assessment of EMP health status pertains to emotional, mental and physical health, respectively. As most of the assessment statements (questions) are simple and self-explanatory, each respondent should take not more than 30 minutes to complete a questionnaire. The preliminary assessment was conducted using printed questionnaires. When the EMPHA system was fully developed, data collected using the manual questionnaire survey, were entered into the system for analysis.

\subsection{Administration of the Questionnaire}

By using the EMPHA system, assessment results are generated immediately after the respondents have submitted their questionnaires online. Also, appropriate treatments are recommended by the EMPHA system depending on the result obtained after answering the second questionnaire. Respondents can record the treatments performed and answer the second questionnaire to know the latest EMP health status after performing treatments for the required duration. If respondents forget to perform and/or record the treatments performed, a reminder email will be sent to them.

\section{Results}

The analyses discuss in this section include the respondents' profiles, the EMP health status of the respondents and investigation on the effectiveness of the treatments recommended for the EMP health problems.

\subsection{Respondents' Profiles}

In this research, a total of 151 medical students, selected randomly from three medical universities in Pakistan, were invited to participate in the study. Of these, 113 (74.8\%) students visited the website, registered themselves and answered the emotional, mental and physical health questionnaires. They will be referred to as respondents. As shown in Table 1, of the 113 respondents, only $96(85.0 \%)$ respondents were required to follow the treatments on regular basis. It is obvious that the majority of the respondents fall under the emotional category followed by physical; and emotional, mental and physical health problems.

Of the 113 respondents, 49 (43.4\%) respondents are male and 64 (56.6\%) respondents are female. As shown in Figure 1, there are $60(53.1 \%)$ female and 44 (38.9\%) male respondents, $4(3.5 \%)$ female and $5(4.4 \%)$ male respondents from the age groups of 22-24 years and 25-28 years, respectively.

Figure 2 shows that a majority of the female respondents $(58,90.6 \%)$ have EMP health problems as compared to the male respondents $(38,77.6 \%)$. This trend could possibly be due to more female (64) than male (49) respondents involved in this study. However, the outcome could also reflect the actual EMP health status of the female medical students as there are only 6 female medical students compared to 11 male medical students who do not have EMP health problems.

Based on Table 1 and Figure 3, a total of 96 respondents who have one or more of the EMP health problems need to undergo treatments. Table 2 shows the types of treatments that these respondents need to perform according to the severity level of the EMP health problems. The number and percentage of respondents who are assigned the specific types of treatments are shown in Figure 3.

\subsection{Reliability Analysis on the Measurement Scale}

The EMP health assessment questionnaires have three sections, namely, emotional, mental and physical sections, with 19, 9 and 11 questions, respectively. To determine the reliability of the data, a statistical analysis known as alpha coefficient, was performed. Alpha (Cronbach) is a model of internal consistency, based on the average inter-item correlation (SPSS Base 14.0 User's Guide, 2005). Inter-item correlation checks the correlation among the questions in each category. In this study, inter-item correlations were determined for each category for both before-treatment and after-treatment cases. Using the reliability analysis, it can be determined as to what extent the items in the questionnaire are related to each other. This is done by ranking the responses using the Likert scale. The lowest scale is 0 and the highest scale is 5. For each of the three EMP health problem categories, the alpha coefficients were calculated, and tabulated in Table 3.

Based on the results shown in Table 3, all treatments investigated have alpha coefficients close to 0.7. The Cronbach's alpha coefficient of below 0.5 suggests that the items are not reliable (SPSS Base 14.0 User's Guide, 2005). Hence, 
these results suggest that there is a high level of internal consistency among the items in each EMP health assessment category, before and after treatment(s).

\subsection{Testing for Normality of Data Distributions}

A critical stage in any data analysis is the test of significance of factors affecting the variables of interest. One-sample Kolmogorov-Smirnov Test compares the observed cumulative distribution function for a variable with a specified theoretical distribution, which may be normal, uniform, exponential, or Poisson. The one-sample Kolmogorov-Smirnov test can be used to prove that a variable is normally distributed, and large significance values $(>0.05)$ indicate that the observed distribution corresponds to the theoretical distribution (SPSS Base 14.0 User's Guide, 2005). Hence, the normality distribution of each of the variables, i.e. emotional, mental and physical health problems, was performed using this test.

The results of the tests, presented in Table 4 , show that all the corresponding $p$-value is greater than 0.05 . If all variables being investigated have $p$-values greater than 0.05 , they reflect that the data follow normal distribution.

\subsection{Effectiveness of the Treatments Applied}

There are two treatments for the emotional category, namely, Soothing the body and the mind (T1), and Collarbone breathing exercise (T2). Soothing the body and the mind (T1) treatment was prescribed for 3 respondents, only. The Collarbone breathing exercise (T2) was prescribed for 70 respondents.

Similarly, there are four treatments for the mental category, namely, Soothing the body and the mind (T1), Psoas exercise (T3), Meridian tap exercise (T4), and What thoughts are ruling your life (T5). In this study, only one treatment, the Psoas exercise (T3), was prescribed for the respondents as they suffer from minor mental problems, and none of them is severe. This treatment was prescribed for 26 respondents.

There are three treatments for the physical category. Only two treatments, namely, Thymus tap exercise (T7) and Zip-up exercise (T6) were prescribed for the respondents. No respondent has severe physical problems that would make it necessary to prescribe the Cross Crawl exercise (T8). The treatment, Thymus tap exercise (T7), was prescribed for 25 respondents. The treatment Zip-up exercise (T6) was prescribed for 26 respondents.

To investigate the effectiveness of the treatments undergone by the respondents, a suitable statistical test can be used. As the data pertaining to the emotional, mental and physical health are normally distributed (Table 4), the paired t-test was chosen to test the hypothesis that there is no difference in the treatments. If the treatments had no effect, the average difference between the measurements is equal to 0 , and the null hypothesis holds. On the other hand, if the treatments did have an effect, the average difference is not 0 , and the null hypothesis is rejected. In this study, the level of significance, defined at $5 \%$, is regarded as a normal acceptable level of significance in social science studies, and is often set at $\mathrm{p}=0.01$ or $\mathrm{p}=0.05$ (SPSS Base 14.0 User's Guide, 2005). To test the effectiveness of treatments, the following null and alternate hypotheses were established.

$\mathrm{H}_{0}$ : Treatments for emotional, mental and physical health problems: T1, T2, T3, T6 and T7 are not effective.

$\mathrm{H}_{1}$ : Treatments for emotional, mental and physical health problems: T1, T2, T3, T6 and T7 are effective.

In this study, respondents who suffer from EMP health problems are grouped into the emotional (E), mental (M) or physical (P) categories, respectively. These three groups of respondents were prescribed relevant treatments/exercises to alleviate their EMP health problems. One assumption made in this test of hypothesis is that all the respondents had undergone and recorded the treatments according to the instructions, and for the recommended duration honestly. This assumption might not be true as there are four possibilities that could happen in data collection:

i. Respondents had undergone the treatments and recorded the treatments;

ii. Respondents had undergone the treatments but did not record the treatments;

iii. Respondents did not undergo the treatments but recorded the treatments;

iv. Respondents did not undergo the treatments and did not record the treatments.

As the significance level has been determined at $\mathrm{p}=0.05$, the errors/bias resulting from cases ii and iii above, have been considered in the test of hypothesis and indicated clearly in the standard deviation and standard error columns of Tab. 5 .

Table 5 shows the results of the paired t-test. The average difference (i.e. the mean column for before and after treatments) for emotional (T1 and T2), mental (T1 and T3), and physical (T6 and T7) health are 0.73756, 0.45299 and 0.64171 , respectively. These values are greater than zero. In paired t-test, a non-zero average difference implies that the treatments performed by the respondents are effective (i.e. improvements in the health conditions). Also, since the significance value for the three EMP health conditions before-after treatments is less than 0.05 (i.e. 0.000 in the last column for all three EMP health problems), we can conclude that the treatments, T1, T2, T3, T6 and T7, are effective, and the improvements in the EMP health conditions of the respondents are not by chance. Hence, the null hypothesis is rejected and the alternate hypothesis is accepted. 


\section{Discussion}

The outcomes of the study reveal that more female (58 out of 64, 90.6\%) medical students suffer from EMP health problems as compared to the male (38 out of $49,77.6 \%$ ) medical students. Based on the statistical paired t-test results, the treatments for emotional health problem, soothing the body and the mind (T1) and Collarbone breathing exercise (T2); and the treatment for physical health problem, soothing the body and the mind (T1) and Psoas exercise (T3); are more effective than the treatments for mental health problems, Zip-up exercise (T6) and Thymus tap exercise (T7). This is reflected by the average difference (i.e. the Mean column in Table 5) of the emotional (0.73756), and physical $(0.64171)$ health scores which are higher than the average difference of the mental health score (0.45299). These results imply that the treatments assigned to the respondents are found to be effective in improving their EMP health problems after performing and completing the recommended treatments regularly, within the specified treatment period.

Often, students who suffer from EMP health problems are afraid or shy to seek expert's help. They are unable to overcome the problems themselves, thus, resulting in tragic incidents such as killing and suicides. The outcomes of this research show that EMP health problems could be overcome by following appropriate exercises/treatments, regularly. Also, the development of the EMPHA system, which incorporates comprehensive EMP assessment techniques of Vera Peiffer, provides an alternative channel to help these students to analyse their EMP health conditions and recommend suitable treatments. Obviously, the research findings and the use of the EMPHA system can contribute to reducing and overcoming these serious health problems that students everywhere, irrespective of their socio-economic status, are facing today. There are definitely areas for further research and enhancement of the EMPHA system such as incorporation of other EMP health assessment techniques, and addition of more treatments into the system, and collection of data from other countries for analysis. 


\section{APPENDIX I}

\section{SELF ASSESSMENT}

EMOTIONAL, MENTAL AND PHYSICAL (EMP) HEALTH QUESTIONNAIRE

DATE:

NAME:

Instructions: Please tick $(\checkmark)$ one box only or specify otherwise.

1. GENDER:
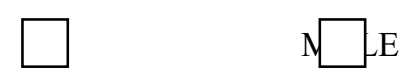

FEMALE

2. AGE GROUP: $\square$

21

$\square \quad 25-28$

$29-32$

3. FIELD OF STUDY:

MEDICAL

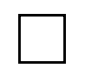

COMPUTER SCIENCE

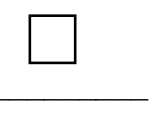

OTHERS,

PLEASE

SPECIFY:

4. PHONE NUMBER:

5. E-MAIL:

6. INSTITUTION NAME:

This questionnaire should not take more than 30 minutes to answer.

\section{Preliminary Test (Pre-Test)}

All the information will be kept confidential. This information will be used for research purpose only.

\section{Instructions}

- Please read through each of the following statement and circle the relevant answer.

\section{Option Interpreter}

Y: This statement applies to me.

$\mathrm{N}$ : This statement does not apply to me. 
Please circle either ' $\mathrm{Y}$ ' or ' $\mathrm{N}$ ' next to each of the statement. We will need it to measure your EMP health condition.

\begin{tabular}{|c|c|c|c|}
\hline No. & Statement & & \\
\hline 1 & I am often in a bad mood. & $\bar{Y}$ & $\mathbf{N}$ \\
\hline 2 & I find it difficult to control my anger. & $\mathbf{Y}$ & $\mathbf{N}$ \\
\hline 3 & I find it hard to say 'no,' even when someone makes unreasonable demands. & $\mathbf{Y}$ & $\mathbf{N}$ \\
\hline 4 & I am a jealous person. & $\overline{\mathbf{Y}}$ & $\mathbf{N}$ \\
\hline 5 & I am easily hurt when I am criticised, even if the criticism is constructive. & $\overline{\mathbf{Y}}$ & $\mathbf{N}$ \\
\hline 6 & It upsets me greatly when I fail at something, no matter how unimportant it is. & $\overline{\mathbf{Y}}$ & $\mathbf{N}$ \\
\hline 7 & I feel I am losing control over my life. & $\overline{\mathbf{Y}}$ & $\mathbf{N}$ \\
\hline 8 & I feel anxious and down a lot. & $\overline{\mathbf{Y}}$ & $\mathbf{N}$ \\
\hline 9 & I can't let go of a past event. & $\overline{\mathbf{Y}}$ & $\mathbf{N}$ \\
\hline 10 & I feel unhappy about lots of things in my life. & $\overline{\mathbf{Y}}$ & $\mathbf{N}$ \\
\hline 11 & I am so emotional that I often find it hard to make rational decisions. & $\overline{\mathbf{Y}}$ & $\mathbf{N}$ \\
\hline 12 & I constantly change my mind. I am a true ditherer. (dither means hesitant) & $\overline{\mathbf{Y}}$ & $\mathbf{N}$ \\
\hline 13 & In certain situations, I panic and am unable to think rationally. & $\mathbf{Y}$ & $\mathbf{N}$ \\
\hline 14 & $\begin{array}{l}\text { I find it difficult to follow a train of thought when I need to take in new } \\
\text { information. }\end{array}$ & $\mathbf{Y}$ & $\mathbf{N}$ \\
\hline 15 & I feel confused and disorientated. & $\mathbf{Y}$ & $\mathbf{N}$ \\
\hline 16 & $\begin{array}{l}\text { I find it difficult to follow instructions. I simply cannot remember the order of } \\
\text { things. }\end{array}$ & $\overline{\mathbf{Y}}$ & $\mathbf{N}$ \\
\hline 17 & I feel constantly tired. & $\mathbf{Y}$ & $\mathbf{N}$ \\
\hline 18 & Whenever there is a bug going around, I will catch it. & $\mathbf{Y}$ & $\mathbf{N}$ \\
\hline 19 & I have been plagued by various health problems for a long time. & $\mathbf{Y}$ & $\mathbf{N}$ \\
\hline 20 & I have a chronic condition which doesn't get better. & $\mathbf{Y}$ & $\mathbf{N}$ \\
\hline 21 & I have a chronic condition which is getting worse. & $\overline{\mathbf{Y}}$ & $\overline{\bar{N}}$ \\
\hline 22 & $\begin{array}{l}\text { I have annoying physical symptoms (ticks, twitches, shooting pains, and so on) } \\
\text { that keep recurring. }\end{array}$ & $\bar{Y}$ & $\mathbf{N}$ \\
\hline 23 & The quality of my skin and/or hair has deteriorated. & $\overline{\mathbf{Y}}$ & $\mathbf{N}$ \\
\hline 24 & My breathing feels different in an unpleasant way. & $\overline{\mathbf{Y}}$ & $\mathbf{N}$ \\
\hline 25 & I feel unwell but can't say exactly how or why. & $\overline{\mathbf{Y}}$ & $\overline{\mathbf{N}}$ \\
\hline 26 & $\begin{array}{l}\text { One or several of my body processes (for example, menstruation, bowel } \mathrm{m} \\
\text { digestion, etc.) has not been working properly for a while. }\end{array}$ & $\begin{array}{c}\mathbf{v e n} \\
\mathbf{Y}\end{array}$ & ents \\
\hline
\end{tabular}

Thank you for your participation. 


\section{APPENDIX II}

SELF-ASSESSMENT

EMOTIONAL, MENTAL AND PHYSICAL (EMP) HEALTH QUESTIONNAIRE

DATE:

NAME:

Instructions: Please tick $(\checkmark)$ one box only or specify otherwise.

1. GENDER:
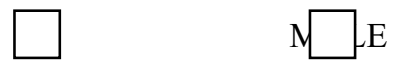

FEMALE

2. AGE GROUP: $\square$

21

$\square \quad 25-28$

$29-32$

3. FIELD OF STUDY:

MEDICAL

COMPUTER SCIENCE

OTHERS,

PLEASE

SPECIFY:

4. PHONE NUMBER:

5. E-MAIL:

6. INSTITUTION NAME:

This questionnaire should not take more than 30 minutes to answer.

\section{EMP Health Assessment (Before and After Treatments)}

All the information will be kept confidential. This information will be used for research purpose only.

\section{$\underline{\text { Instructions }}$}

- Please read through each of the following statement and rate them according to how relevant they are to your situation using the rating scale given below.

\section{$\underline{\text { Rating Scale }}$}

A: This statement applies to me 100 per cent.

B: This statement reflects how I feel quite often.

C: I sometimes feel like this and it upsets me.

D: I sometimes feel like this but it does not bother me.

E: I rarely feel like this.

F: This statement does not apply to me.

Please circle your rating next to each of the statement. We will need it to measure your EMP health status. 


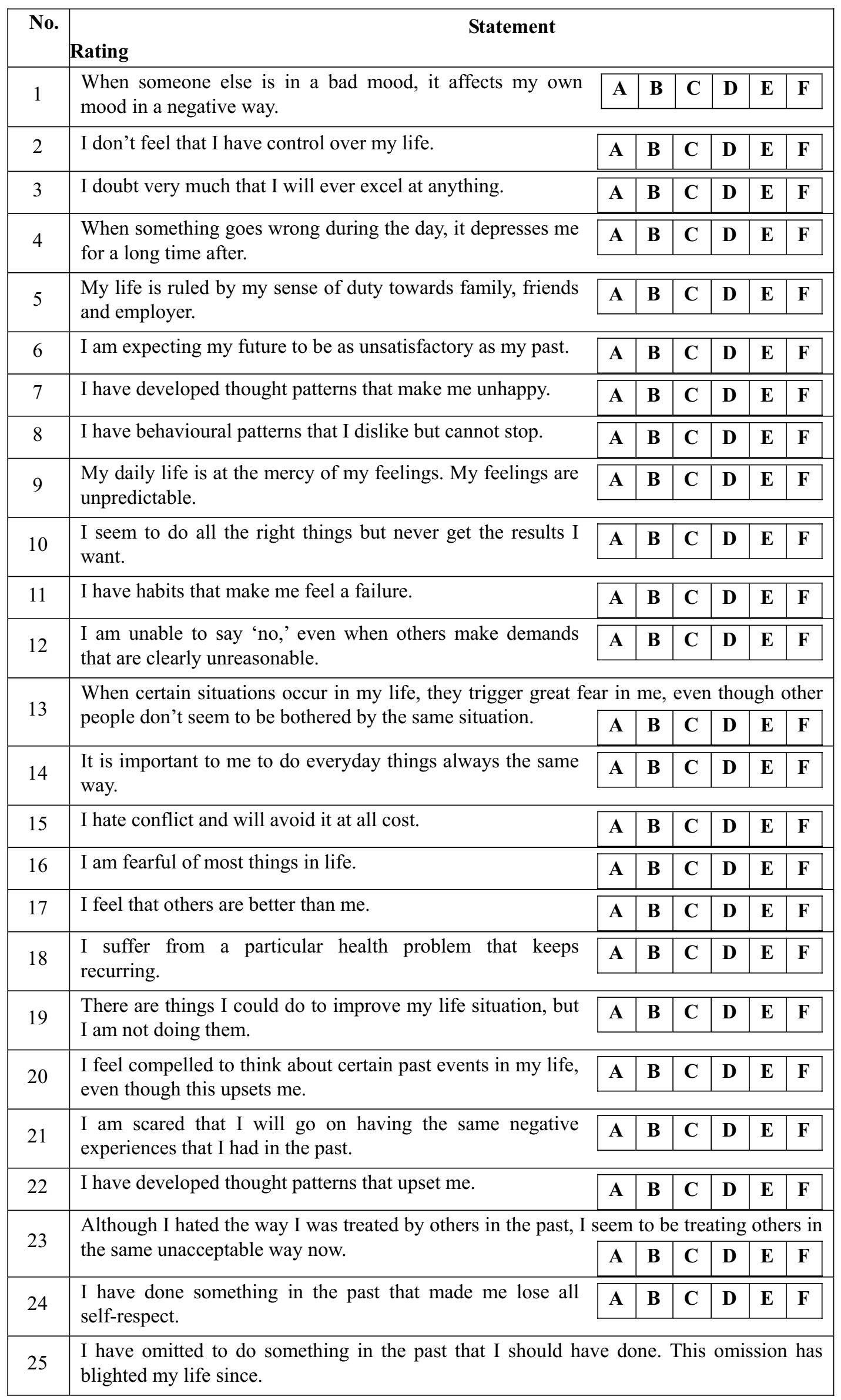




\begin{tabular}{|c|c|c|c|c|c|c|c|}
\hline \multirow[t]{2}{*}{ No. } & \multicolumn{7}{|l|}{ Statement } \\
\hline & & $\mathbf{A}$ & B & $\mathbf{C}$ & D & $\mathbf{E}$ & $\mathbf{F}$ \\
\hline 26 & $\begin{array}{l}\text { I often have unexpected flashbacks about a past traumatic } \\
\text { event. }\end{array}$ & $\mathbf{A}$ & B & $\mathbf{C}$ & $\mathbf{D}$ & $\mathbf{E}$ & $\mathbf{F}$ \\
\hline 27 & I cannot remember anything before the age of ten. & $\mathbf{A}$ & $\mathbf{B}$ & $\mathbf{C}$ & D & $\mathbf{E}$ & $\mathbf{F}$ \\
\hline 20 & \multicolumn{7}{|c|}{ I have a chronic illness and now I feel guilty because someone said that I have attracted } \\
\hline 28 & the illness through negative thoughts. & A & B & $\mathbf{C}$ & D & $\mathbf{E}$ & $\mathbf{F}$ \\
\hline 29 & I would rather be anyone else but myself. & $\mathbf{A}$ & B & $\mathbf{C}$ & $\mathbf{D}$ & $\mathbf{E}$ & $\mathbf{F}$ \\
\hline 30 & \multicolumn{7}{|c|}{ I have brief moments where I see disturbing pictures in my mind which do not seem to } \\
\hline 50 & relate to anything I have experienced in my life so far. & $\mathbf{A}$ & B & $\mathbf{C}$ & $\mathbf{D}$ & $\mathbf{E}$ & $\mathbf{F}$ \\
\hline 21 & \multicolumn{7}{|c|}{ I have been trying to think positively over a long time, but somehow, it doesn't work for } \\
\hline I & me. & $\mathbf{A}$ & B & $\mathbf{C}$ & D & $\mathbf{E}$ & $\mathbf{F}$ \\
\hline 32 & $\begin{array}{l}\text { When I look back over my life and think of where I am } \\
\text { today, I am dissatisfied. }\end{array}$ & $\mathbf{A}$ & B & $\mathbf{C}$ & $\mathbf{D}$ & $\mathbf{E}$ & $\mathbf{F}$ \\
\hline 33 & My thoughts are automatically negative most of the time. & $\mathbf{A}$ & B & $\mathbf{C}$ & D & $\mathbf{E}$ & $\mathbf{F}$ \\
\hline 34 & I cannot see a future. & $\mathbf{A}$ & B & $\mathbf{C}$ & D & $\mathbf{E}$ & $\mathbf{F}$ \\
\hline 35 & $\begin{array}{l}\text { I don't think I can visualise. I just don't have any } \\
\text { imagination. }\end{array}$ & $\mathbf{A}$ & B & $\mathbf{C}$ & D & $\mathbf{E}$ & $\mathbf{F}$ \\
\hline 36 & I don't like who I have become. & $\mathbf{A}$ & B & $\mathbf{C}$ & D & $\mathbf{E}$ & $\mathbf{F}$ \\
\hline 37 & I don't think others like me. & $\mathbf{A}$ & B & $\mathbf{C}$ & D & $\mathbf{E}$ & $\mathbf{F}$ \\
\hline 38 & I dislike myself and I resent others. & $\mathbf{A}$ & B & $\mathbf{C}$ & D & $\mathbf{E}$ & $\mathbf{F}$ \\
\hline 39 & $\begin{array}{l}\text { I feel it is important to hide my inadequacies from others } \\
\text { around me. }\end{array}$ & $\mathbf{A}$ & B & $\mathbf{C}$ & D & $\mathbf{E}$ & $\mathbf{F}$ \\
\hline
\end{tabular}

Thank you for your participation. 


\section{Acknowledgement}

The authors would like to acknowledge the participation of the medical students of Baqai Medical University, Dow University of Health Sciences, and Sindh Medical College in the questionnaire surveys; the kind assistance and cooperation from friends, parents, and the general public who provided valuable feedback and comments throughout the research.

\section{References}

Arthur, N. (1998). The effects of stress, depression, and anxiety on postsecondary students' coping strategies. Journal of College Student Development, 39 (1), 11-22.

AsiaOne News. (2007). Malaysian year six pupil found hanged [Online] Available: http://www.asiaone.com/News/Education/Story/A1Story20071119-37440.html.

Dass, F. (2007). A healthy mind in a healthy body [Online] Available: http://www.psychiatry-malaysia.org/article.php?aid=711.

Haines, M.E., Norris, M.P., \& Kashy, D.A. (1996). The effect of depressed mood on academic performance in college students. Journal of College Student Development, 37 (5), 519-526.

Hopkins, A., \& Zengerle, P. (2008). thestar online: South Korean student blamed for U.S. shooting rampage [Online] Available:

http://thestar.com.my/news/story.asp?file=/2007/4/17/ worldupdates/2007-04-17T194000Z_01_NOOTR_RTRJONC_0_-294547-2\&sec=Worldupdates.

Inam, S.N., Saqib, A., \& Alam, E. (2003). Prevalence of anxiety and depression among medical students of private university. Journal of Pakistan Medical Association, 53 (2), 44-47.

PakTribune. (2008). Student commits suicide for not securing good marks in SSC exam [Online] Available: http://www.paktribune.com/news/index.shtml?185829.

Peiffer V. (2002). Inner Happiness: Positive Steps to Feeling Complete. London: Judy Piatkus (Publishers) Limited.

Quantum Flow. (2007). What is quantum flow bioenergetics [Online] Available: http://www.quantumflow.com/index.php?option=com_content\&task=view\&id=5\&Itemid=4.

South West Clear Mind. (n.d.). Thought Field Therapy [Online] Available: http://www.southwestclearmind.co.uk/?page_id=4.

SPSS Base 14.0 User's Guide. (2005). Chicago: SPSS Inc.

Thomson Reuters. (2008). Student gunman blamed for U.S. campus shooting [Online] Available: http://www.reuters.com/article/latestCrisis/idUSN17367451.

Zensight Energy Healing. (2005). [Online] Available: http://www.zensightprocess.com/. 
Table 1. Cross-tabulation of Gender with EMP Health Problems

\begin{tabular}{|l|c|c|c|}
\hline \multirow{2}{*}{ Health Problem } & \multicolumn{2}{|c|}{ Gender } & \multirow{2}{*}{ Total } \\
\cline { 2 - 4 } & Female & Male & 17 \\
\hline None & 6 & 11 & $(15.0 \%)$ \\
\hline Emotional & $(9.4 \%)$ & $(22.4 \%)$ & 41 \\
& 25 & 16 & $(36.3 \%)$ \\
\hline Physical & $(39.0 \%)$ & $(32.7 \%)$ & 22 \\
& 13 & 9 & $(19.5 \%)$ \\
\hline Emotional and Mental & $(20.3 \%)$ & $(18.4 \%)$ & 4 \\
& 0 & 4 & $(3.5 \%)$ \\
\hline Emotional and Physical & $(0.0 \%)$ & $(8.2 \%)$ & $(6.2 \%)$ \\
\hline Mental and Physical & 6 & 1 & 1 \\
& $(9.4 \%)$ & $(2.0 \%)$ & $(0.9 \%)$ \\
\hline Emotional, Mental and Physical & 0 & 1 & 21 \\
& $(0.0 \%)$ & $(2.0 \%)$ & $(18.6 \%)$ \\
\hline
\end{tabular}

This table shows the distribution of the emotional, mental, and physical health problems of the respondents by gender.

Table 2. Types of Treatments According to Severity Level of EMP Health Problems

\begin{tabular}{|l|l|l|l|l|l|l|l|l|l|l|}
\hline \multirow{2}{*}{ Treatment/Exercise } & \multicolumn{7}{|c|}{ Health Problems } \\
\hline & \multicolumn{2}{|c|}{ Emotional } & \multicolumn{3}{|c|}{ Mental } & \multicolumn{3}{c|}{ Physical } \\
\hline & L & M & H & L & M & H & VH & L & M & H \\
\hline Soothing the body and the mind (T1) & $\checkmark$ & & $\checkmark$ & & $\checkmark$ & & & & & \\
\hline Collarbone breathing exercise (T2) & & $\checkmark$ & $\checkmark$ & & & & & & & \\
\hline Psoas exercise (T3) & & & & $\checkmark$ & & & & & & \\
\hline Meridian tap exercise (T4) & & & & & & $\checkmark$ & & & & \\
\hline What thoughts are ruling your life (T5) & & & & & & & $\checkmark$ & & & \\
\hline Zip-up exercise (T6) & & & & & & & & $\checkmark$ & & \\
\hline Thymus tap exercise (T7) & & & & & & & & & $\checkmark$ & \\
\hline Cross crawl exercise (T8) & & & & & & & & & & $\checkmark$ \\
\hline
\end{tabular}

Keys: L - Low Severity, M - Medium Severity, H - High Severity, VH - Very High Severity

This table shows the different types of treatment/exercise for emotional, mental and physical health problems based on the severity level. 
Table 3. Reliability Coefficients

\begin{tabular}{|l|c|c|}
\hline Item & Number of Questions in Each Category & Alpha Coefficient \\
\hline 1) Before treatment & 19 & 0.659 \\
\hline Emotional & 9 & 0.687 \\
\hline Mental & 11 & 0.693 \\
\hline Physical & \multicolumn{3}{|l|}{} \\
\hline 2) After treatment & 19 & 0.692 \\
\hline Emotional & 9 & 0.686 \\
\hline Mental & 11 & 0.679 \\
\hline Physical & 9 & \\
\hline
\end{tabular}

This table shows the Alpha Coefficients for the emotional, mental and physical health before- and after-treatment. All the values are greater than 0.5 , implying that all the items have a high level of consistency in each assessment category.

Table 4. Results of Kolmogorov-Smirnov Test

\begin{tabular}{|l|c|c|}
\hline Variable & Test Statistics & $p$-value \\
\hline Before-Treatment & 0.993 & 0.278 \\
\hline Emotional & 0.950 & 0.327 \\
\hline Mental & 1.123 & 0.160 \\
\hline Physical & & 0.567 \\
\hline After-Treatment & 0.786 & 0.702 \\
\hline Emotional & 0.706 & 0.368 \\
\hline Mental & 0.918 & \\
\hline Physical & & \\
\hline
\end{tabular}

This table shows the values of the test statistics for emotional, mental and physical health conditions of the respondents before and after performing treatments using the Kolmogorov-Smirnov Test. The values of the test statistics of after-treatment are smaller than before-treatment, implying that the treatments/exercises for emotional, mental and physical health are effective. 
Table 5. Results of Paired t-test (Emotional, Mental and Physical Health Problems)

\begin{tabular}{|c|c|c|c|c|c|c|c|c|c|}
\hline & & \multicolumn{5}{|c|}{ Paired Differences } & \multirow[t]{3}{*}{$\mathrm{t}$} & \multirow[t]{3}{*}{$\mathrm{df}$} & \multirow{3}{*}{$\begin{array}{c}\text { Sig. } \\
\text { (2-tailed) }\end{array}$} \\
\hline & & \multirow[t]{2}{*}{ Mean } & \multirow[t]{2}{*}{$\begin{array}{c}\text { Std. } \\
\text { Deviation }\end{array}$} & \multirow[t]{2}{*}{$\begin{array}{c}\text { Std. } \\
\text { Error }\end{array}$} & \multicolumn{2}{|c|}{$\begin{array}{l}95 \% \text { Confidence } \\
\text { Interval of the } \\
\text { Difference }\end{array}$} & & & \\
\hline & & & & & Lower & Upper & & & \\
\hline $\begin{array}{l}\text { Pair } \\
1\end{array}$ & $\begin{array}{l}\text { Emotional } \\
{[\text { Before-Af }} \\
\text { ter] }\end{array}$ & .73756 & .32827 & .03842 & .66097 & .81415 & 19.197 & 72 & .000 \\
\hline $\begin{array}{l}\text { Pair } \\
2\end{array}$ & $\begin{array}{l}\text { Mental } \\
{[\text { Before-Af }} \\
\text { ter] }\end{array}$ & .45299 & .32949 & .06462 & .31991 & .58608 & 7.010 & 25 & .000 \\
\hline $\begin{array}{l}\text { Pair } \\
3\end{array}$ & $\begin{array}{l}\text { Physical } \\
\text { [Before-Af } \\
\text { ter] }\end{array}$ & .64171 & .35741 & .05005 & .54119 & .74223 & 12.822 & 50 & .000 \\
\hline
\end{tabular}

This table shows the mean difference of the emotional, mental and physical health conditions of the respondents before and after performing treatments. The results imply that their EMP health conditions have improved after performing treatments.

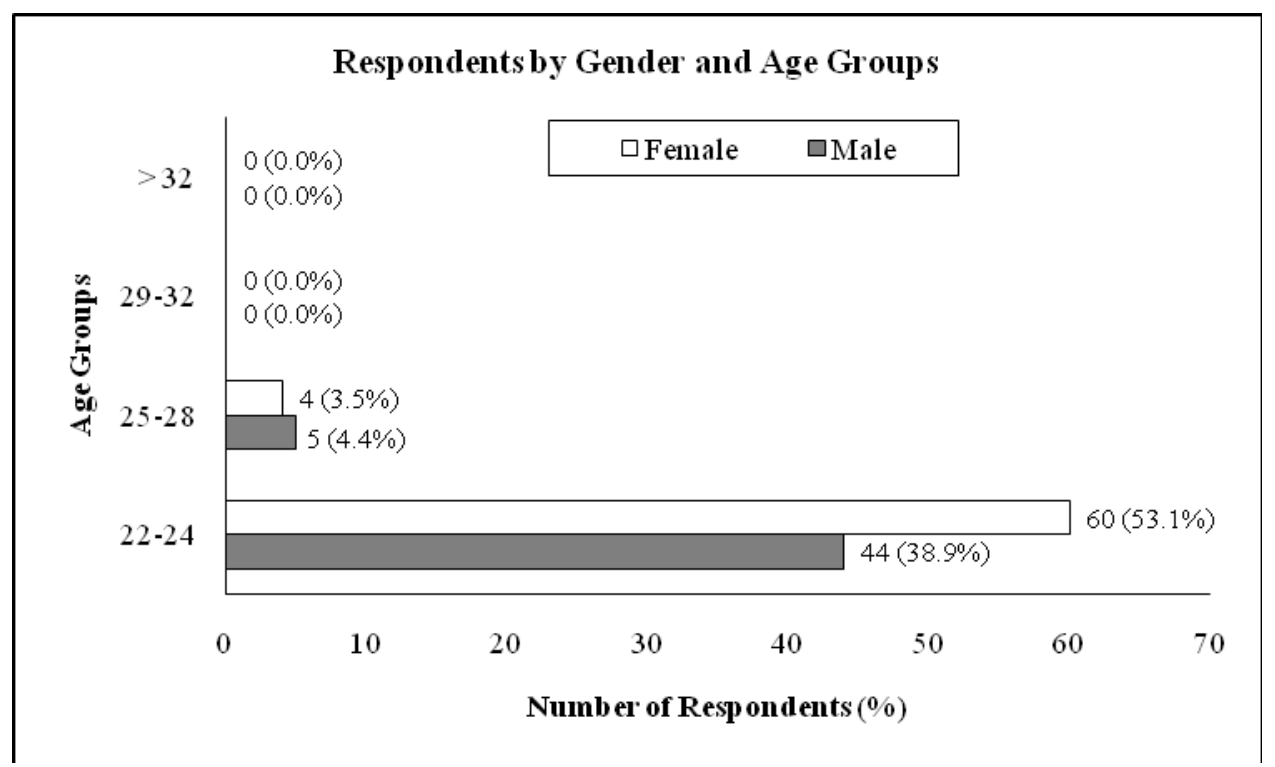

Figure 1. Respondents by Gender and Age Groups

This figure shows the distribution of the respondents by gender and age groups. 
Keys:

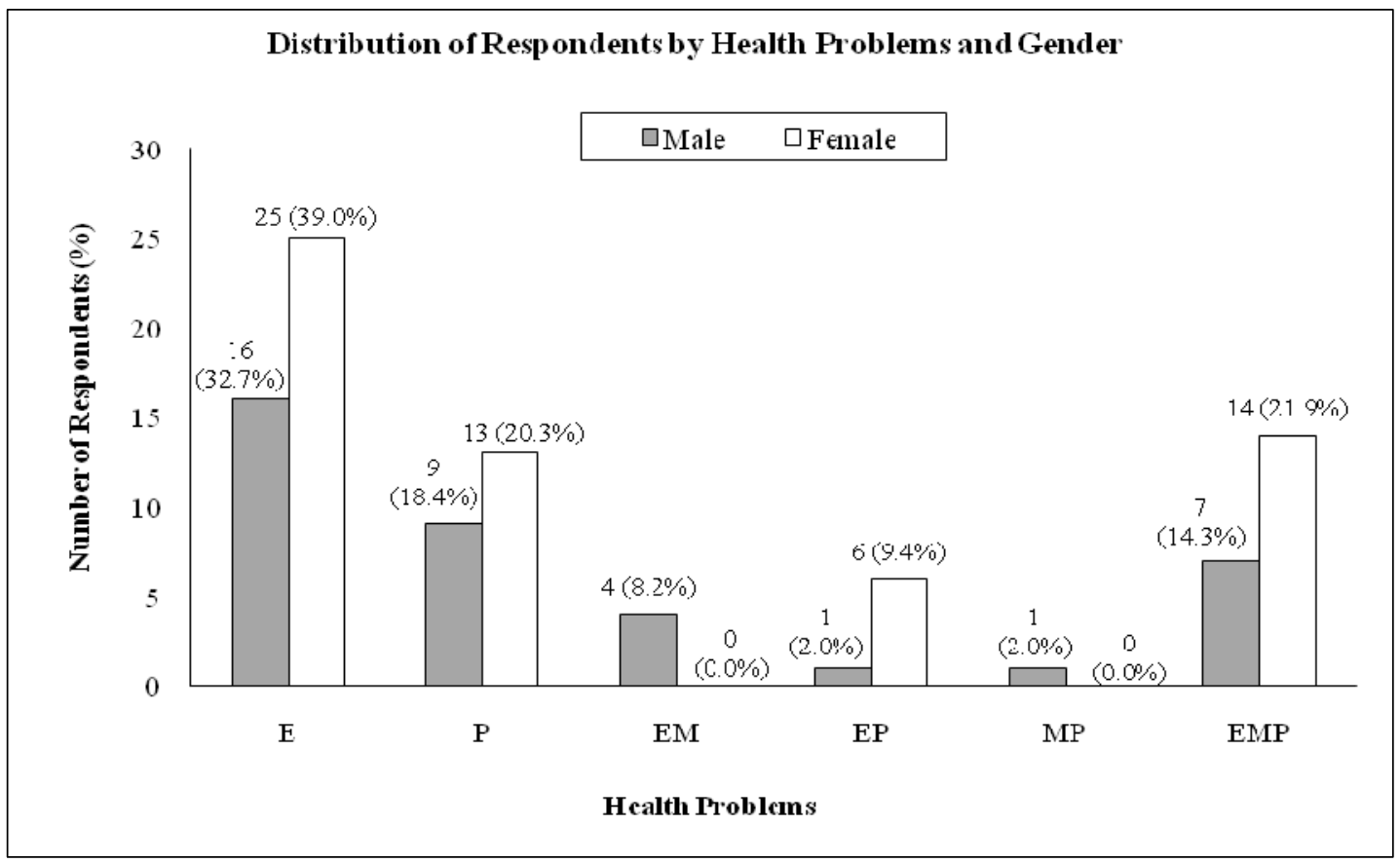

E-Emotional, M-Mental, P-Physical, EM-Emotional and Mental, EP-Emotional and Physical, MP-Mental and Physical, EMP-Emotional, Mental and Physical

Figure 2. Respondents by Gender and Health Problems

This figure shows the distribution of the respondents by health problems (emotional, mental and physical) and gender.

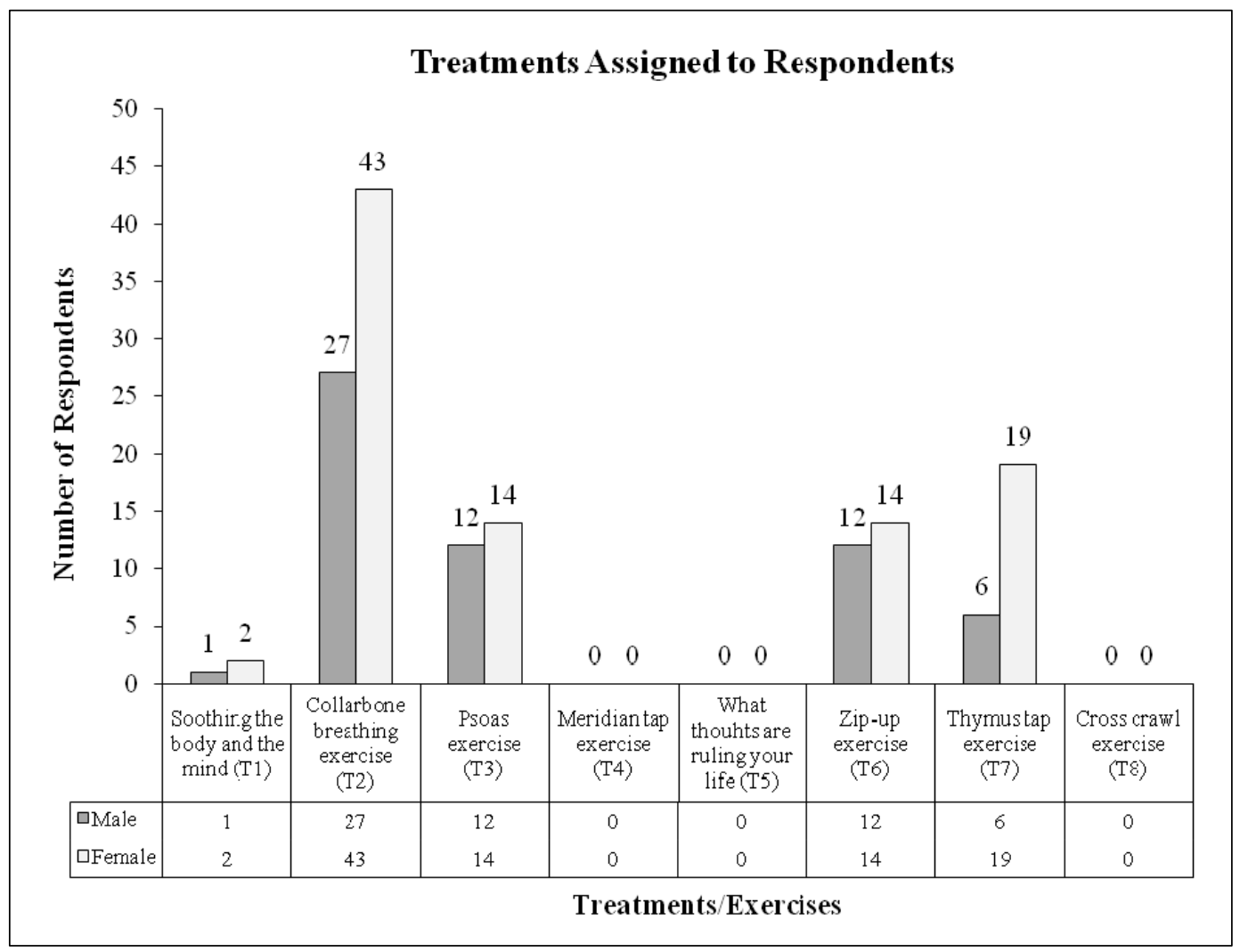

Figure 3. Respondents by Gender and Types of Treatments Assigned

This figure shows the types of treatment assigned to the respondents according to their respective emotional, mental and physical health problem and severity level. 